Histoire de l'éducation

$122 \mid 2009$

L'enseignement supérieur

\title{
ALBANESE (Ralph), Corneille à l'école républicaine : du mythe héroïque à l'imaginaire politique en France, 1800-1950
}

Paris : L'Harmattan, 2008, 365 p.

\section{Anne-Marie Chartier}

\section{OpenEdition}

\section{Journals}

Édition électronique

URL : https://journals.openedition.org/histoire-education/1953

DOI : 10.4000/histoire-education. 1953

ISSN : 2102-5452

Éditeur

ENS Éditions

Édition imprimée

Date de publication : 1 avril 2009

Pagination : 118-121

ISBN : 978-2-7342-1151-8

ISSN : 0221-6280

\section{Référence électronique}

Anne-Marie Chartier, « ALBANESE (Ralph), Corneille à l'école républicaine : du mythe héroïque à

l'imaginaire politique en France, 1800-7950 », Histoire de l'éducation [En ligne], 122 | 2009, mis en ligne le 27 octobre 2009, consulté le 20 mai 2021. URL : http://journals.openedition.org/histoire-education/ 1953 ; DOI : https://doi.org/10.4000/histoire-education.1953

Ce document a été généré automatiquement le 20 mai 2021.

(c) Tous droits réservés 


\section{ALBANESE (Ralph), Corneille à l'école républicaine: du mythe héroïque à l'imaginaire politique en France, 1800-1950}

Paris : L'Harmattan, 2008, 365 p.

\section{Anne-Marie Chartier}

\section{RÉFÉRENCE}

ALBANESE (Ralph), Corneille à l'école républicaine: du mythe héroïque à l'imaginaire politique en France, 1800-1950, Paris : L'Harmattan, 2008, 365 p.

1 Dans la série des recherches sur la construction des canons scolaires, voici une nouvelle contribution de Ralph Albanese, qui nous a déjà offert Molière à l'école républicaine (1992) et La Fontaine à l'école républicaine (2003). Ce spécialiste américain des French Studies, professeur à l'Université de Memphis, a naturellementun regard distancié : il n'a pas eu à apprendre une tirade par an ni à répudier Le Cid après mai 1968, qui fut le tombeau du vieux Corneille et de Gustave Lanson. De cette aura scolaire éteinte, il est possible de faire l'histoire. L'ouvrage la déroule en deux moments, celui de la réception critique des écrivains, dont les célébrations fabriquent les classiques, et celui des usages scolaires.

Années 1800-1850: Napoléon vénère Corneille («Messieurs, s’il vivait, je le ferais prince »), Chateaubriand réhabilite Polyeucte, les romantiques reviennent sur le dénigrement de Voltaire (pour eux, Corneille est notre Shakespeare). Le Cid, représenté 240 fois entre 1800 et 1848, réunit dans une commune admiration Hugo, Stendhal, Sainte-Beuve. C'est à cette époque que les premières histoires littéraires (La Harpe, Nisard, Saint-Marc Girardin) isolent la "tétralogie » (Le Cid, Horace, Cinna, Polyeucte) qu'on mettra au menu des classes sous Jules Ferry. Mais c'est sous le Second Empire 
qu'apparaît le "Grand Corneille ", patriote unanimement prôné par les lectures pourtant antagonistes de monarchistes, de bonapartistes et de républicains.

Entre la défaite de Sedan et l'armistice de 1918, les Lettres deviennent des « marqueurs d'identité nationale » : Corneille entre au Panthéon républicain et enseigne, aux élèves des lycées laïques comme à ceux des bons Pères, l'amour sacré de la patrie. Ralph Albanese a lu les très nombreux ouvrages qui ont forgé une vulgate durable autour des quatre chefs d'œuvre, validant au passage la définition « chervelienne » de la discipline scolaire. Au milieu de tant de noms oubliés, on trouve les vedettes du genre, Emile Faguet (Corneille expliqué aux enfants, 1885), Brunetière ("Corneille a haussé l'âme française au-dessus d'elle-même»), Lanson (qui en fait un «maître de morale » bien nécessaire en une période de " crise de la volonté »).

Dans les années 1930, les lectures cornéliennes de Péguy nourrissent les jeunes générations de khâgneux, accompagnés aussi par Desjardins et Bellessort. Pourtant, la gloire de Corneille est déjà vacillante. Brasillach, qui le déplore (Pierre Corneille, 1938), oppose la rébellion belliqueuse des jeunes héros (Rodrigue, Horace, Cinna) à l'égoïsme calculateur de leurs aînés. Corneille aurait ainsi fondé l'idéologie du pouvoir monarchique, prototype poétique du fascisme moderne : « le pire des États, c'est l'État populaire ", dit Cinna. Comme d'Annunzio face à Mussolini, Corneille serait le chantre du totalitarisme du Roi Soleil. Il faudra attendre Morales du Grand Siècle (1948) pour que Paul Bénichou défasse ces projections rétrospectives du présent sur le passé, en montrant au contraire à quel point l'éthique chevaleresque des héros cornéliens a eu d'autant plus de succès sur la scène qu'elle était la représentation nostalgique d'une féodalité disparue.

5 La gloire scolaire de Corneille vient donc de ce qu'il a pu nourrir des imaginaires politiquement divergents autour de fictions, présentées comme historiques, mettant en intrigue la question du pouvoir, de la guerre, de l'État. C'est là que s'affrontent des volontés conflictuelles, alors que chez Racine s'entredéchirent des passions contradictoires : si l'on veut "former la jeunesse », la cause est entendue, Corneille ne peut qu'être gagnant. Du moins, tant que le salut de la patrie est à l'ordre du jour, ce qui est le cas dans les années fondatrices de l'école républicaine, entre 1880 et 1920. Dans le corpus de plus de 130 manuels listés en annexe, 60 sont parus entre 1880 et 1900,33 entre 1900 et 1920 , soit les trois quarts. Le dernier quart se distribue inégalement, 26 avant Sedan, 37 entre 1920 et 1950 (date butoir de l'ouvrage). Au-delà, Albanese cite tout de même 17 titres (2 seulement de 1980 à nos jours). Cette répartition éloquente doit être reliée à la bibliographie de "critique exégétique " (187 titres). Les études récentes qui ont tant enrichi la lecture de Corneille (Antoine Adam, Paul Bénichou, Georges Couton, Bernard Dort, Serge Doubrovsky, Marc Fumaroli et nombre d'études de langue anglaise) ont toutes réinséré Corneille dans son siècle, rejetant de facto le mythe du chef d'œuvre "éternel », car fondé sur la description pérenne d'une nature humaine immuable. Or c'est ce lieu commun qui a nourri l'enseignement jusqu'aux années 1960.

6 Sous Jules Ferry, le Corneille des manuels traditionalistes de la droite, qui « exaltent les vertus d'ordre et de discipline ", n'est pas tout à fait celui des manuels de la gauche, qui insistent "sur les valeurs de solidarité et d'universalisme républicain ». Mais ils visent tous, "par le biais d'une vision idéalisée du théâtre cornélien, à faire ressortir ses vertus pédagogiques: la primauté de la raison, la mise en valeur de la volonté, la hauteur morale, la glorification des valeurs passéistes et le rôle de l'éthique héroïque 
au sein de la conscience nationale des Français» (p. 177). Corneille ouvre donc une porte sur l'imaginaire collectif. Les Américains voyaient dans les citations scolaires de nos dirigeants ( "Je le ferais encore si j'avais à le faire»), l'indice d'une déférence nationale envers la littérature, alors qu'aux États-Unis un président citera les psaumes, mais pas les poètes. Corneille aurait donné aux républicains leur «idéal de transcendance héroïque » (pour parler comme Faguet), idéal qui survivrait encore dans la recherche de modèles à offrir à l'admiration des jeunes ou dans le culte si français des grands hommes. La pérennité de dilemmes "cornéliens" qu'affronte tout responsable politique qui se respecte signalerait toujours sa présence, fantomatique, dans un paysage où s'effacent les fictions du Grand Siècle. Un trait de la "francité » se dévoilerait dans les us et abus d'une culture chrétienne, aristocrate et monarchiste, que la laïcité républicaine militante aurait paradoxalement perpétuée dans la figure des chefs d'État. Ralph Albanese souligne ainsi que Pétain et de Gaulle « se sont inspirés du dramaturge et ont, chacun à leur manière, récupéré sa rhétorique ». Interrogé sur sa pièce préférée, de Gaulle répondit : «Suréna. Il y est question du conflit du devoir et de la passion, qui se résout par le suicide. [...] Savez-vous que je peux comprendre ce type de réaction. À Dakar... eh bien !, j'ai moi aussi été effleuré par cette idée » (p. 316).

7 C'est qu'on pouvait alors plaquer sur la patrie en danger le conflit de la raison contre l'honneur. Passé l'euphorie de la Libération, les accents cornéliens sont vite suspectés de pompe et d'emphase. L'enquête scolaire s'arrête dans les années 1950, quand la guerre d'Algérie, "guerre sans nom " peu glorieuse, défait l'idée de sacrifice du côté français (au contraire des Algériens prêts à mourir pour l'indépendance ou des généraux passés à l'OAS). L'idéal héroïque meurt définitivement avec mai 1968, "révolte contre le prix de la grandeur », conduisant à la méditation désenchantée d'Auguste («Et monté sur le trône...»).

Comment faire lire Corneille quand s'effrite le mythe de la France éternelle, de la France résistante, de la France "mère des arts, des armes et des lois", pays de la Révolution et des droits de l'homme, en même temps que disparait la sacralité des textes classiques? Ralph Albanese s'interroge in fine sur la persistance de cette rhétorique de l'honneur national, qui déborde l'extrême droite, avec le discours enflammé de Nicolas Sarkozy contre la «France qui tombe » et pour la France qui gagne, à travers ses prouesses ou ses martyrs (Guy Môquet, jeune héros sacrifié). Malgré le succès de cette héroïsation discursive qui flatte la vanité hexagonale, Albanese s'interroge sur la réelle capacité des Français «à réintégrer le patriotisme au sein de leur conscience politique ». En revanche, il ne dit rien de la langue de Corneille, qui a pourtant été un point d'achoppement essentiel pour l'enseignement secondaire de masse. Ce serait le déphasage entre l'idéologie cornélienne et la montée de l'individualisme consumériste qui expliquerait le discrédit de cet auteur dans les années 1960.

9 Pour lui, une telle exaltation de l'héroïsme républicain a fait la pertinence ancienne de Corneille, mais ne fait pas espérer le retour en grâce des tirades en alexandrins. Cependant, son livre est paru avant que le Président ne brocarde la (toute cornélienne) Princesse de Clèves, persiflant les enseignants élitistes qui osaient la faire lire et la proposer en sujet d'examen. Résultat : ce dernier ouvrage connaît un succès de librairie persistant depuis. On ne se méfie jamais assez des classiques. 